\title{
Project Management as an Essential Core Competency in Engineering
}

\author{
J. Michael Bennett \\ University of Ontario Institute of Technology \\ michael.bennett@uoit.ca
}

\author{
Danny Ho \\ NFA Estimation Inc. \\ danny@nfa-estimation.com
}

\section{Introduction}

Project management is emerging as perhaps the key core competency in Engineering in the $21^{\text {st }}$ century industrial workplace. We developed two project management courses (basic and advanced) for the Faculty of Engineering as special topic courses that will prepare students and professionals to apply project management discipline in their study and work. The courses are intensive investigations into the major principles of project management slanted towards, but not exclusively about, the management of engineering projects. We use the Project Management Institute's (PMI's) Project Management Body of Knowledge (PMBoK) $4^{\text {th }}$ Edition [1] as a skeleton and expand that coverage to IEEE's Project Management Standard [2] and British Standards Institute's (BSI's) Standard [3]. The courses also cover relevant examples and several case studies from the industry. There is significant class interaction. Each student researches a current topic in an area of choice and gives a formal presentation and report. We have offered these courses to universities and companies in multiple countries, as well as government institutions.

We also conducted a survey as part of a recent course offering to study the impact of technology to future professionals. We would like to validate whether some basic human fundamentals that directly impact project management, such as punctuality, keeping appointments, honouring commitments, and most importantly honesty, have been honoured or ignored by the upcoming generation of engineers.

We argue that these courses should be classified as core in engineering education, highlight the contents of the courses and interpret the results of the survey in this paper.

\section{Purpose}


Board (CEAB). In industry, there are too many engineers who tumbled into project management without proper and adequate training. (That is why we have offered our training to companies around the world and to government institutions.) Unfortunately, in the real world, while on-the-job training is always available, failure will not be tolerated more than once, even though knowledge can only be gained in a hit-ormiss fashion. Trial and error effort will result in costly mistakes. In today's competitive market, there is only one standard for success - excellence. The discipline of project management is no exception.

We also offer this course at the graduate level for similar reasons. A number of graduate students are new immigrants to this country and they have professional experience from other countries. While pursuing advanced engineering degrees, the course also prepares them for the PMI's Project Management Professional (PMP) Examination. With work experience and examination accreditation, those who eventually attain the PMP status (which is recognized worldwide), are in better positions to continue with their career in the local job market.

We cannot stress enough that engineering project management is the core of the engineering curriculum.

\section{The Basic Course}

This course is offered to second year software engineering students as an introduction to the methods and procedures for managing engineering projects. It covers the basics of PMBoK units 1,2,3,6,7 and 9; with emphasis on project planning, scheduling, cost estimation, project organizational types and staffing, managing engineering professionals, as well as measuring and controlling projects. At the end of the course, students are expected to be proficient in managing one's individual tasks as well as team activities, to be prepared to manage third and fourth year individual and team projects, and to be ready to undertake internship professional opportunities in their areas of engineering.

We are not going to repeat the contents of PMBoK, but merely highlighting some of our offerings and findings.

\section{Project Management Stories}

Each student was asked to research a unique project management story and give a 5-minute presentation. This exercise kicked off the course and students learned to appreciate the importance of project management.

Project Planning and Scheduling
We asked students (either as an assignment or as a mid-term examination question) to derive a Work Breakdown Structure (WBS) and schedule (with activities sequencing, milestones and external dependencies) capturing the moment they woke up until they arrived at the university. Students felt that the exercise benefited their understanding of how to manage themselves and how to conduct better planning in the future.

Cost Estimation

We discussed the Performance Evaluation and Review Technique (PERT) for estimation. We also introduced students to the concepts of Function Points [4], Rayleigh Model, Exponential Model, Constructive Cost Model (COCOMO) [5] and Software Life Cycle Management (SLIM) [6], as well as practical experience with these estimation models. Students were exposed to the magnitude of large, medium and small projects in the industry in terms of cost, time and staff estimation.

Project Organization Types and Staffing

Students only knew about functional organizations. They were not aware of matrixed and projectized organizations. We discussed the pros and cons of each type of organization and of being an engineer in these organizations.

Managing Engineering Professionals

We discussed the hiring and firing processes. We also discussed human behaviour by introducing the Blanchard [7], Fundamental Inter-Personal Relationship Orientation Behaviour (FIRO-B) [8], Myers-Briggs [9], Parker [10] and Porter [11]. We used Thomas-Kilmann Conflict Model Instrument [12] when covering conflict management. Students acknowledged that they knew more about themselves and felt comfortable coping with others with different behaviour and temperament.

Measuring and Controlling Projects

The concept of earned value (EV) was new to all students. It took many examples and exercises to convey the concept, and for students to recognize the usefulness of cost variance $(\mathrm{CV})$, schedule variance (SV), cost performance index (CPI), schedule performance index (SPI), etc.

\section{$\underline{\text { Case Studies }}$}

Each student researched a topic or experience report on project management, gave a 15-minute presentation (with questions and answers period) and wrote a 5page report.

\section{The Advanced Course}

This course is offered to fourth year and graduate engineering students, as well as professionals about to 
practice or practising project management in industry. It provides detailed coverage of all PMBoK units (112), the IEEE project management standard, ethics, etc. At the end of the course, students are expected to be proficient in engineering project management and to be ready to write the PMP examination. Again, we are not going into details of $\mathrm{PMBoK}$, but merely highlighting some of our offerings and findings.

\section{Project Initiation}

We discussed engineering economics and project management in building successful proposals to sanction projects. This was complementary to the Engineering Economics core course.

\section{Project Management Artifacts}

We asked students to derive a project charter for their fourth year, Master's or Ph.D. thesis. Students believed that such a contract between them and their supervisors was highly beneficial. As the final project of the course and upon completion of most lectures, students were asked to derive full project management plans (PMPs) for their capstone theses. Both the students and their supervisors saw the benefits of writing and maintaining the project plans.

Project Scope Management

We asked students to consult their supervisors and establish a Change Control Board (CCB), usually the capstone thesis supervisory committee, to monitor and approve changes on their theses. (Students liked the idea, some supervisors did not!)

Project Cost Management

For software engineering students, we introduced novel estimation techniques such as a neural-fuzzy algorithm [13] for those who might be interested in advanced research.

\section{Project Quality Management}

This was complementary to the Software Quality Assurance course and provided a management viewpoint on quality planning, assurance and control.

\section{Human Resource Management}

We discussed downsizing and the more commonly used term, rightsizing. These topics elicited the most class participation and even brought up discussions outside the scope of the course.

Project Procurement Management

We discussed offshoring and outsourcing. Again, these topics elicited much class discussion (many of our students are immigrants). Just like any project, we discussed the need to go through initiating, planning, execution, monitoring and controlling, and closing for any offshoring and outsourcing projects. We also analyzed the cost and benefits of these projects.

\section{Case Studies}

Each student researched a topic or experience report on project management, gave a 1-hour presentation (with questions and answers period) and wrote a 15page report.

PMP Mock Examination

Upon completion of each PMBoK unit, we assigned some PMP-type multiple choice questions to students. Similar types of questions were part of the mid-term and final examination, which acted as a mock PMP examination.

\section{The Survey}

There is no silver bullet to successful project management. Taking our training and following $\mathrm{PMBoK}$ or other standards will surely lead to running projects with less risks and higher probabilities of success. Nevertheless, there is no replacement to some basic human fundamentals, such as punctuality, keeping appointments, honouring commitments, and most importantly honesty; refer to Figure 2 (which is analogous to Figure 1).

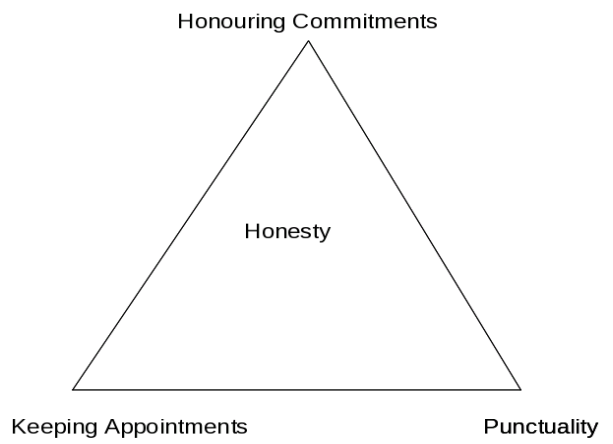

Figure 2. Basic human fundamental triples

As part of the recent course offering, we conducted a survey (based on a real life example) to study the impact of technology on these human fundamentals for the upcoming generation. We like to tease our students by saying that two individuals, while walking inside a shopping mall, were so busy texting each other to find out where they were that eventually they bumped into each other "heads on". While technology has enabled communications easily, would overreliance on technology create "the tool and a fool" problem? Is the upcoming generation seeing lastminute changes via technology to appointments and commitments as part of the norm?

Our survey was targeted towards the upcoming generation, specifically the undergraduate and graduate students, who would attain their professional designations shortly after graduation. Although participation is entirely optional, we received 118 enthusiastic responses, with just a few opt-out. There 
were 10 multiple choice questions that would take less than 5 minutes to answer. There were no right or wrong answers. Instant responses were the best answers. The Appendix listed the questions. The answers ranged from ratings of very likely (5), somewhat likely (4), neutral (3), somewhat unlikely (2), to very unlikely (1). The results were normalized and presented as percentages ranging from very likely $(100 \%)$ to very unlikely $(0 \%)$.

Table 1. Results of survey

\begin{tabular}{|c|c|c|c|}
\hline Questions & Scores (\%) & Questions & Scores (\%) \\
\hline 1 & 51 & 6 & 65 \\
\hline 2 & 85 & 7 & 76 \\
\hline 3 & 68 & 8 & 87 \\
\hline 4 & 68 & 9 & 58 \\
\hline 5 & 60 & 10 & 64 \\
\hline
\end{tabular}

We are not going to repeat the questions, but merely highlighting our interpretation of the results.

Q1. In hectic and adverse moments, half of the group will forget about their commitments. The result is rather astonishing! Note that these are just answers on paper. In real life situations, more will forget! Note how we presented the importance of this commitment: deemed unimportant to the provider but how about the requester?

Q2 and Q3. Luckily, a very high percentage will notify the other party in advance and a high percentage will honour the make-up session.

Q4 and Q6. These questions bring up the "tool and a fool" scenario. There was one written comment asking whether the other party actually received the email. One does not know, and what does one do about it?

Q5 and Q10. These questions follow the Porter assessment when one is being challenged (or cornered). It appears that the upcoming generation does not have a high level of tolerance.

Q7 and Q8. We feel relieved by the high percentages for these answers - feeling guilty and making up the omission.

We also present some written comments. On one hand, we note the following.

"Person X should also realize people have some other things to do and should not put too much pressure on anyone."

"X seems like parents in this situation. I feel that parents may be understanding and their demands and expectations are not high.”
"I no longer care to discuss the matter."

On the other hand, we note the following.

"I try to meet all commitments and hope to do so in the future."

"The issue here is very poor time management skills, lack of foresight and pro-activity; causing these scheduling problems in the first place. There is no reason for a 15-30 minute phone appointment to be missed.”

"I am a reasonably organized person and have never had so much work that I could not find time, and plan around a 15-30 minutes call. I meet my commitments.”

We have also received feedback from many that they are frustrated by the overuse and misuse of technology. It appears that the majority of the group is still observing the basic human fundamentals of courtesy. However, we realize that we have only solicited answers on paper, in an artificial environment. In real life situations, the actual circumstances can influence the scores. The bottomline is: how do you manage these professionals? What are their approaches to management and how do they manage in the future?

\section{Discussion}

We have been grateful to develop two project management courses. The basic course provides an introduction to project management. The advanced course can be tailored as a fourth year course, graduate course, or professional training in the industry. We received positive comments from many who passed the PMP examination after taking our training. Based on the results of positive course evaluations, good news on PMP examination results and informal student feedbacks, we feel that engineering project management is well on the way to becoming a key core competency in engineering, just as the CEAB's OBA initiative requires.

Basic human fundamentals form the backbone of successful project management. The results of our survey reaffirm that these fundamentals are still observed and followed by the majority of engineering students. We will continue to stress their importance as part of our project management course offerings.

\section{References}

[1] Project Management Institute, Project Management Body of Knowledge, $4^{\text {th }}$ Edition, PMI, 2008.

[2] Institute of Electrical and Electronics Engineers, IEEE Standard 10581-1987, IEEE, 1987. 
[3] British Standards Institute, BS6079-1:2010 Project Management Principles and Guidelines for the Management of Projects, BSI, 2010.

[4] A. Albrect, "Measuring Application Development Productivity”, Proceedings of the Joint SHARE/GUIDE/IBM Application Development Symposium, 1979.

[5] B, Boehm et. al. Software Cost Estimation with COCOMO II, Prentice Hall, 2000.

[6] L. Putnam, and W. Myers, Measures for Excellence, Yourdan Press Computing Series, 1992.

[7] K. Blanchard, D. Carew, and E. Parisi-Carew, The One Minute Manager Builds High Performance Teams, William Morrow and Company, 1990.

[8] W. Schutz, FIRO Scales Manual, CA: Consulting Psychologists Press, 1967.

[9] K. Myers, and L. Kirby, Introduction to Type Dynamics and Development, CA: Consulting Psychologists Press, 1994.

[10] G. Parker, Cross-Functional Teams, Jossey-Bass, 1994.

[11] E. Porter, Strength Deployment Inventory, Personal Strength Publishing, 1992.

[12] K. Thomas, and R. Kilmann, Thomas-Kilmann Conflict Mode Instrument, Xicom, 1996.

[13] X. Huang, D. Ho, J. Ren, and L.F. Capretz, System and Method for Software Estimation, US Patent \# US-7328202B2, 2008.

\section{Appendix - Survey Questions}

Background: X has been helping you a lot throughout your lifespan of twenty-some years. You made a commitment to $\mathrm{X}$ to discuss matters (deemed unimportant to you) over the phone for 15-30 minutes on a certain day.

Q1. During your hectic and adverse moments (assignments due, term test approaching, feeling lonely and depressed), how likely is it for you to forget about the commitment?

Q2. Suppose you did not forget about the commitment, yet you knew you could not make it. How likely is it for you to notify $\mathrm{X}$ prior to or on the committed date?

Q3. Suppose X was quite understanding and agreed with you to postpone the discussion to a later date. You were still caught in a spiral of more hectic moments and adverse events. How likely is it for you to meet this postponed commitment (still deemed unimportant to you)?
Q4. Suppose you knew you could not make it and sent an e-mail to $\mathrm{X}$ requesting further delay. Unfortunately, due to timing issues in communication (e-mail delay, different time zones), no confirmation or acknowledgement was received from X. How likely is it for you to notify $\mathrm{X}$ via other means of communication (e.g., phone call) prior to the scheduled date and time?

Q5. At the same time, you were caught in an afterschool event in the evening. All students attended a presentation by a potential employer. The presentation started more than an hour late and was going to overrun till almost 11 p.m. With your current study load, you needed the time this evening to finish some assignments due the next day. How likely is it for you to walk out of this presentation?

Q6. Considering your commitment to X, suppose your e-mail requesting further delay was never acknowledged and you did not attempt to notify $\mathrm{X}$ via other means of communication. During the afterschool presentation (started late and overran), it was also time for you to have the 15-30 minutes phone discussion with $\mathrm{X}$. How likely is it for you to get out of the presentation briefly and notify $\mathrm{X}$ of your situation?

Q7. Suppose you stayed at the presentation till the end and never made an effort to call $\mathrm{X}$. By the time you arrived home, still having to finish the assignments due the next day, still have not had dinner, etc., you saw an angry e-mail from $\mathrm{X}$ after waiting for your call and blaming you for repeatedly missing your commitments. How likely is it for you to feel being at fault?

Q8. How likely is it for you to apologize and commit to a date/time that you would try your very best not to miss again?

Q9. How likely is it for you to sort through your grievances (study load, depression, etc.) and use these as your excuses of missing your commitments?

Q10. Suppose you poured your heart out, only to be met with more furious responses from $\mathrm{X}$, saying that you were incapable and irresponsible. How likely is it for you to de-commit from the 15-30 minutes discussion with $\mathrm{X}$, seeing that you have too many important and higher priority items to handle? 